\title{
$\nabla$
}

\section{Relationship between acne vulgaris and attention-deficit/hyper- activity disorder symptoms in a clinical sample of women*}

\author{
Ayhan Bilgic ${ }^{1}$ \\ Rukiye Sivri Çolak ${ }^{1}$
}

\author{
Özlem Bilgic ${ }^{2}$ \\ Hilmi Cevdet Altınyazar ${ }^{2}$
}

DOI: http://dx.doi.org/10.1590/abd1806-4841.20164613

\begin{abstract}
Acne vulgaris has recently been reported to be associated with elevated rates of attention deficit/hyperactivity disorder in epidemiological studies. This report examines childhood and current attention-deficit/ hyperactivity disorder symptoms in a clinical sample of female adults. Ninety-one women with acne vulgaris and 53 controls were included in this study. The aforementioned symptoms were measured in participants. No significant differences were found between patients and controls in any of the measurements. Contrary to the findings of epidemiological studies, this study did not uncover a link between acne vulgaris and attention-deficit/ hyperactivity disorder.
\end{abstract}

Keywords: Acne vulgaris; Attention deficit disorder with hyperactivity; Female

Acne vulgaris (AV) is a chronic, multifactorial skin disease that affects the majority of the population. Although data are not universal, studies have generally reported that depression, anxiety, and psychological stress are higher among AV patients than in healthy controls. ${ }^{1,2}$ Recently, two epidemiological studies reported that $\mathrm{AV}$ is also related to an elevated rate of attention-deficit/hyperactivity disorder (ADHD).,4

ADHD is a childhood-onset neuropsychiatric disorder characterized by inattention, hyperactivity, and impulsivity, and it is strongly associated with increased rates of psychiatric comorbidity. ${ }^{5}$ Thus, the presence of ADHD has been said to contribute to the serious psychiatric problems in $\mathrm{AV}$ patients. ${ }^{1}$ Furthermore, the putative link between AV and ADHD may reflect a common etiological risk factor among these conditions, such as exposure to higher androgen levels in early development.

To our knowledge, no studies have confirmed the association between AV and ADHD in a clinical setting. This study aimed to explore whether AV is related to current or childhood ADHD symptoms in a clinical sample of female patients.
This study was approved by the Institutional Review Board, and informed consent was obtained from all participants. They comprised women with AV who had attended the dermatology outpatient clinic, and healthy controls. The control group was selected from the local community. None of the controls had a history of $\mathrm{AV}$, other androgen-related skin diseases, or major physical illnesses.

Acne severity was assessed using the International Consensus Conference on Acne Classification System. ${ }^{6}$ The Adult ADHD Self-Report Scale (ASRS) and the Wender Utah Rating Scale (WURS) were used to evaluate patients' current and childhood ADHD symptoms, respectively. The ASRS consists of 18 items that contain inattention and hyperactivity subscales, as well as a total score. ${ }^{7}$ The WURS includes subscales for irritability, depression, school problems, behavioral problems/impulsivity, and attention deficits. ${ }^{8}$

Data were analyzed using the SPSS 21.0 statistical software (Chicago, IL, USA). Differences between groups were analyzed with the Student $t$-test or the Mann-Whitney U test. Pearson and Spearman 
TABLE 1: Comparisons of psychiatric test scores in clinical and control samples

\begin{tabular}{|c|c|c|c|c|}
\hline & $\begin{array}{l}\text { Patients } \\
(\mathrm{n}=91)\end{array}$ & $\begin{array}{l}\text { Controls } \\
(n=53)\end{array}$ & t or $z$ & $p$ \\
\hline \multicolumn{5}{|l|}{ WURS } \\
\hline Irritability & $6.8 \pm 5.8$ & $6.4 \pm 6.0$ & $0.36 \mathrm{a}$ & 0.717 \\
\hline Depression & $4.2 \pm 3.5$ & $3.9 \pm 3.0$ & $0.34 \mathrm{~b}$ & 0.732 \\
\hline School problems & $1.2 \pm 1.7$ & $1.2 \pm 1.7$ & $0.08 \mathrm{~b}$ & 0.939 \\
\hline Behavioral problems/impulsivity & $2.3 \pm 2.8$ & $3.3 \pm 3.2$ & $-1.93 \mathrm{~b}$ & 0.056 \\
\hline Attentional deficits & $5.7 \pm 3.4$ & $5.3 \pm 2.8$ & $0.84 \mathrm{a}$ & 0.903 \\
\hline Total & $20.2 \pm 13.9$ & $20.1 \pm 12.9$ & $0.10 \mathrm{~b}$ & 0.920 \\
\hline \multicolumn{5}{|l|}{ ASRS } \\
\hline Inattention & $13.2 \pm 4.9$ & $11.7 \pm 4.5$ & $1.81 \mathrm{a}$ & 0.072 \\
\hline Hyperactivity & $13.0 \pm 4.9$ & $13.1 \pm 5.2$ & $-0.13 a$ & 0.913 \\
\hline Total & $26.2 \pm 9.0$ & $24.8 \pm 8.1$ & $0.94 \mathrm{a}$ & 0.349 \\
\hline
\end{tabular}

WURS $=$ Wender Utah Rating Scale; ASRS = Adult ADHD Self-Report Scale. a Student $\mathrm{T}$ test; $\mathrm{b}$ Mann-Whitney $\mathrm{U}$ test.

coefficients were applied to analyze correlations between psychological test scores and clinical characteristics, as appropriate. The significance level was set at $p<0.05$.

The study population consisted of a total of 91 female AV patients and 53 healthy controls. The mean age did not differ significantly between the patient (22.2 \pm 4.3 years) and control ( $22.4 \pm 4.4$ years) groups (range: $18-38$ years; $\mathrm{z}=-0.74 ; p=0.456$ ). Educational levels were also similar in AV (13.3 \pm 3.0 years) and control $(13.7 \pm 2.9$ years) groups (range: $5-17$ years; $\mathrm{z}=-0.96 ; p=0.338)$. Most patients had mild acne $(48.3 \%, n=44)$, followed by moderate acne $(46.2 \%, n=$ $42)$, and severe acne $(5.5 \%, n=5)$.

No significant differences were found between the study and control groups for WURS or ASRS scores (Table 1). The correlations between AV severity and psychological test scores were evaluated for the patient group. Only the WURS irritability subscore revealed a correlation with illness severity $\left(r_{\mathrm{s}}=0.24, p=0.025\right)$.

This study tested the hypothesis that ADHD symptoms would increase in women with AV. Contrary to previous epidemiological reports, we did not detect any relationship between AV and ADHD symptoms in the clinical samples. Furthermore, except for childhood irritability, ADHD symptoms were not linked to acne severity.

Gupta et al. retrospectively evaluated an epidemiologically representative sample and found that, compared with other dermatologic conditions, $\mathrm{AV}$ was over twice as likely to be associated with ADHD. ${ }^{3}$ The authors suggested that ADHD could be partly responsible for the higher incidence of psychiatric morbidity and suicidal behaviors in acne patients. Concurrent with this study, a prospective, population-based epidemiologic study has shown an association between severe acne and ADHD in adolescents. ${ }^{4}$ However, our study's findings did not support the relationship between AV and ADHD in the clinical sample. Previous studies that demonstrated a positive link between AV and ADHD either did not perform a structured interview or did not use a validated questionnaire to assess ADHD., ${ }^{3,4}$ Hence, we suggest that conflicting findings between our study and previous ones may stem from these methodological differences.

ADHD is regarded as having a neurodevelopmental origin, and it is not expected to develop secondarily to the psychosocial burden of AV. Thus, understanding the putative relationship between ADHD and AV may be valuable and help in identifying common etiological factors among these conditions. Although the etiopathogenesis of ADHD is unclear, some authors hold that there may be a causal relationship with androgen exposure in early life. ${ }^{9}$ Androgens, through androgen receptors, also play an important role in AV development. ${ }^{10}$ Furthermore, a recent study supports the role of prenatal androgens in $\mathrm{AV}^{\prime}$ 's pathogenesis in females. ${ }^{10}$ We submit that if the association between ADHD and AV is confirmed, this relationship may be related to increased androgen exposure in early life.

Our study has some limitations, including a lack of male samples. Moreover, no structured interviews were performed in either the study or control group, while our data were based only on self-reported questionnaires.

In conclusion, this study did not support the view that $A V$ is related to ADHD. Future studies are needed to better clarify the relationship between $\mathrm{AV}$ and ADHD.] 


\section{REFERENCES}

1. Halvorsen JA, Stern RS, Dalgard F, Thoresen M, Bjertness E, Lien L. Suicidal ideation, mental health problems, and social impairment are increased in adolescents with acne: a population-based study. J Invest Dermatol. 2011;131:363-70.

2. Kamamoto Cde S, Hassun KM, Bagatin E, Tomimori J. Acne-specific quality of life questionnaire (Acne-QoL): translation, cultural adaptation and validation into Brazilian-Portuguese language. An Bras Dermatol. 2014;89:83-90.

3. Gupta MA, Gupta AK, Vujcic B. Increased frequency of Attention Deficit Hyperactivity Disorder (ADHD) in acne versus dermatologic controls: analysis of an epidemiologic database from the US. J Dermatolog Treat. 2014;25:115-8

4. Silverberg $\mathrm{Jl}$, Silverberg NB. Epidemiology and extracutaneous comorbidities of severe acne in adolescence: a U.S. population-based study. Br J Dermatol. 2014;170:1136-42.

5. Becker SP, Luebbe AM, Langberg JM. Co-occurring mental health problems and peer functioning among youth with attention-deficit/hyperactivity disorder: a review and recommendations for future research. Clin Child Fam Psychol Rev. 2012;15:279-302.

6. Pochi PE, Shalita AR, Strauss JS, Webster SB, Cunliffe WJ, Katz HI, et al. Report of the Consensus Conference on Acne Classification. Washington, D.C., March 24 and 25, 1990. J Am Acad Dermatol. 1991;24:495-500.

7. Dogan SÖB, Saraçoglu GV, Küçükgöncü $S$. Validity and reliability of the Turkish version of the Adult ADHD Self-Report Scale (ASRS-v1.1). Anatol J. Psychiatry. 2009; 10:78-87.

8. Oncü B, Olmez S, Sentürk V. Validity and reliability of the Turkish version of the Wender Utah Rating Scale for attention-deficit/hyperactivity disorder in adults. Turk Psikiyatri Derg. 2005;16:252-9.

9. Liu J, Portnoy J, Raine A. Association between a marker for prenatal testosterone exposure and externalizing behavior problems in children. Dev Psychopathol. 2012;24:771-82.

10. Bilgiç Ö, Doğdu M, İslamoğlu GK, Altınyazar C. The relationship between the second to fourth digit ratio and acne vulgaris. J Eur Acad Dermatol Venereol. 2014;28:1340-3.
MAILING ADDRESS:

Ayhan Bilgic

Necmettin Erbakan Üniversitesi Meram Tıp Fakültesi

Çocuk ve Ergen Psikiyatrisi Anabilim Dalı

42090 Meram

Konya, Turkey.

E-mail: bilgicayhan@yahoo.com

How to cite this article: Bilgic A, Bilgic Ö, Sivri Çolak R, Altınyazar HC. Relationship between acne vulgaris and attention-deficit/hyperactivity disorder symptoms in a clinical sample of women. An Bras Dermatol. 2016:91(2):250-2. 